\title{
Los grabadores e ilustradores de las encuadernaciones industriales de la Real Academia de Bellas Artes de San Fernando
}

The engravers and illustrators of the industrial bindings of the Royal Academy of Fine Arts of San Fernando

\section{Antonio Carpallo Bautista (1), Yohana Yessica Flores Hernández (2)}

(1) Facultad de Ciencias de la Documentación de UCM, C/ Santísima Trinidad 37 28010, acarpall@ucm.es (2) amoxtlan@gmail.com

\begin{abstract}
Resumen
El presente estudio tiene como objetivo principal dar a conocer a los artífices de las encuadernaciones industriales realizadas entre los siglos XIX y XX, depositadas en la Biblioteca de la Real Academia de Bellas Artes de San Fernando. Para la elaboración de este tipo de encuadernaciones es preciso contar con un trabajo previo de diseño y grabado de las planchas que se utilizarán para la ornamentación de las tapas y lomos. Además de las tareas ligatorias llevadas a cabo por un encuadernador, también en este tipo de encuadernaciones tiene mucha importancia la participación de dos profesionales que no habían aflorado en la construcción ni ornamentación de una encuadernación hasta la fecha, como son los ilustradores/diseñadores y los grabadores. Ambos serán los que den forma a los diseños de las encuadernaciones, muchas de ellas denominadas parlantes, al transmitir con su ornamentación el contenido de la obra. La Real Academia de Bellas Artes de San Fernando dispone de un rico e interesante fondo de encuadernaciones industriales con las firmas del encuadernador, grabador e ilustrador, algunos de ellos españoles y otros extranjeros.
\end{abstract}

Palabras clave: Edad contemporánea. Real Academia de Bellas Artes de San Fernando. Encuadernación industrial. Grabadores. Ilustradores. España.

\section{Introducción}

La encuadernación industrial, también es llamada encuadernación en serie, comercial, de librero, aunque la más habitual en la actualidad es la de encuadernación de editor, conlleva procesos mecanizados y de producción en serie en su mayor parte. A partir de la Revolución Industrial, en el siglo XIX, se dio un salto cualitativo importante a consecuencia de un incremento de la actividad editorial y por la aparición de mejoras tecnológicas en máquinas, materiales y utillaje, que abarataron los costos de producción de los libros encuadernados. En el aspecto decorativo, y en sus orígenes en el siglo XIX, su principal característica fue la aplicación de planchas con prensas o volantes de dorar, utilizando películas

\begin{abstract}
The main objective of this study is to make known the architects of the industrial bookbinding carried out between the 19th and 20th centuries and deposited in the Library of the Royal Academy of Fine Arts of San Fernando. For the elaboration of this type of binding it is necessary to have a previous work of design and engraving of the plates that will be used for the ornamentation of the covers and spines. In addition to the binding tasks carried out by a bookbinder, also in this type of bookbindings the competition of two professionals who had not appeared in the construction or ornamentation of a bookbinding to date, such as illustrators/designers and engravers, is very important. Both will be the ones who shape the binding designs, many of them called speakers, by transmitting the content of the work with their ornamentation. The Royal Academy of Fine Arts of San Fernando has a rich and interesting collection of industrial bookbindings with the signatures of the bookbinder, engraver and illustrators, some of them Spanish and others foreign.
\end{abstract}

Keywords: Contemporary Age. Spain. San Fernando Royal Academy of Fine Arts (Spain). Industrial binding. Engraving. Illustrators.

doradas, de color, entre otras, generalmente sobre telas. La producción industrial del libro en ese momento se basaba en el trabajo con abundante mano de obra, siendo lo más avanzado en mecanización el volante de dorar y la guillotina.

No obstante, muchas tareas se comenzaron a mecanizar por medio de máquinas como por ejemplo la de preparar las telas de las tapas, la gofradora para adornar las tapas, la plegadora, la de coser, la de redondear y enlomar, la de fabricar tapas y la de alzar. El taller de Pedro Doménech i Saló fue uno de los primeros en introducir en España, hacia 1860 , una maquinaria moderna formada por cizallas, prensas y guillotinas. También destacó el taller de Hermenegildo Miralles. Los soportes más empleados en los recubrimientos 
fueron el papel, la tela (percalina) y la piel (badana); en cuanto a las técnicas de decoración y estampado, se prefirió el gofrado, el dorado y el mosaico, sobre todo con papeles y pieles. Los motivos ornamentales de las encuadernaciones industriales no difieren de los que adornan los libros de lujo, es decir, los estilos decorativos fueron imitados, aunque realizados en serie.

Este trabajo forma parte de los resultados de los Proyectos de investigación I+D (MINECO), titulado "La encuadernación española en las Reales Academias: encuadernadores, talleres y tipologías ligatorias (S. XVIII-XX)" (HAR2017-83387) (2018-2021) y del Proyecto financiado por la Universidad Complutense y el Banco Santander dentro de los proyectos 2016-2017 con el título "Las encuadernaciones de la Real Academia de Bellas Artes de San Fernando: estudio, digitalización, identificación y difusión" (PR26/16-20257), junto a las cláusulas incluidas en el convenio firmado en 2012 entre la Real Academia de Bellas Artes de San Fernando y el grupo Bibliopegia de la Universidad Complutense de Madrid, para el estudio de las encuadernaciones de la Biblioteca, Archivo, Museo y Calcografía Nacional.

\section{Objetivos y metodología}

El objetivo del trabajo se centra en la identificación y estudio de los grabadores e ilustradores que trabajaron en las encuadernaciones de editor, de finales del siglo XIX y primeras décadas del $X X$, y que custodia la RABASF. De su estudio podemos conocer las fechas de sus colaboraciones, con quienes trabajaban (encuadernadores, editores...) conociendo mejor la historia de la edición, del libro y de la encuadernación.

El estudio comenzó con la confección de un inventario de todas las encuadernaciones artísticas de los diferentes fondos, haciendo un análisis detallado de los materiales empleados, técnicas de construcción, técnicas y estructuras decorativas y estado de conservación, además, en el caso de las encuadernaciones industriales o de editor, se identificaron los antiguos poseedores y sobre todo los encuadernadores, grabadores e ilustradores, y también se digitalizaron las encuadernaciones inventariadas.

Ya hace mucho tiempo que en la "Encyclopédie Diderot et D'Alambert, imprimerie reliure" se reimprimió el Recueil de planches, sur les sciences, las arts libéraux et les arts méchaniques, avec leur explication en la que se ilustraban a detalle algunos de los procesos que tienen que ver con la confección de un libro y de su encuadernación. No obstante, en cuanto a la encuadernación se refiere, aún quedan en el anonimato o en el olvido, el reconocimiento de abastecedores de la materia prima y de operarios, como es el caso de curtidores, diseñadores de papeles, doradores, e incluso proveedores de papel, telas y madera. Apenas hace un siglo y medio, que surgen las encuadernaciones industriales, y en las tapas comienzan a aparecer menciones de autoría diferentes de la del encuadernador, por ejemplo ilustrador o grabador; sin embargo hoy en día, aún es difícil encontrar dicha información en las fichas de los catálogos o inventarios.

\section{Grabadores}

Uno de los actores más importantes en el desarrollo de las encuadernaciones industriales han sido los grabadores de planchas de bronce o zinc que estampaban los diseños de los ilustradores mediante tintas y barnices en los recubrimientos de las tapas, ya fueran telas o papeles. Este sistema fue cambiando a partir de 1880 , de la mano de grabadores como Auguste Souze y su sobrino Paul, que introdujeron el sistema del fotograbado, industrializando aún más la producción de los libros y de las encuadernaciones.

En la colección de la RABASF estudiada y que analizamos el grabador con más autorías identificadas fue Josep Roca i Alemany con 28 planchas elaboradas, Paul Souze con diez, Auguste Souze con tres, Francesc Jorba con dos y con solo un diseño Robert Harbaus, haciendo un total de 44 encuadernaciones con la firma del grabador.

El primero de los grabadores del que hablamos es Josep Roca i Alemany (1865-1937), el artista grabador más importante de la época, que una vez formado en la Lloja de Barcelona, se trasladó a Francia y Alemania para continuar con su formación como grabador de planchas de bronce. En esta labor comenzó con pequeñas planchas continuando después con sistemas de fotograbado, planchas esteriotipadas o galvanizadas. Trabajó para gran parte de las casas editoriales del momento como Montaner y Simón, Espasa, Daniel Cortezo, Salvatella, Sopena, Seix, Salvat, Segui y Sucesores de Ramírez.

Diseñó también algunas de sus planchas, como la que hizo para la revista Álbum Salón, primera revista española ilustrada en color. Para el taller de Hermenegildo Miralles realizó la mayoría de las planchas de la Biblioteca Universal Ilustrada de la editorial Montaner y Simón, aunque algunas de ellas fueron realizadas por el grabador José Tersol, diseñadas por los ilustradores Alexandre de Riquer, Josep Triadó, Josep Pascó y Adriá Gual, entre otros, y estampadas en una o dos tintas. También realizó las planchas de las obras de la colección Biblioteca Clásica Española (18841890), siendo el diseñador o ilustrador Josep 
Vilaseca, y las de La llustración Artística "Figura 1", diseñadas por Josep Pascó en 1891.
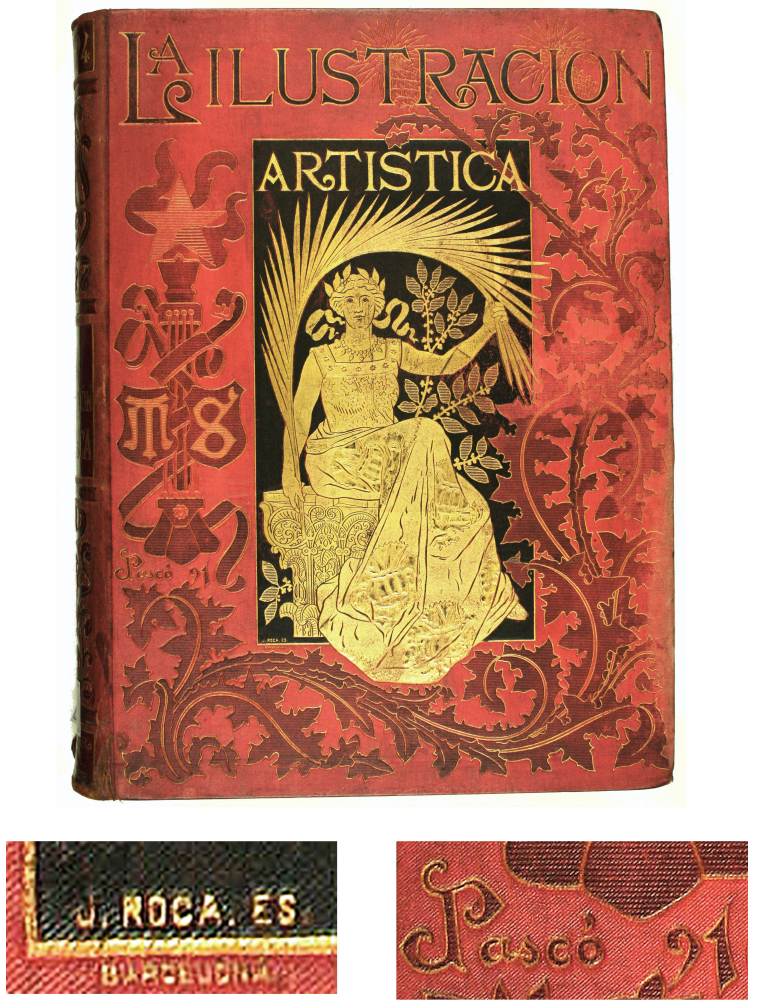

Figura 1. La Ilustración Artística, T. XIII, año 1894 (Sig. G-47 1894). Firmas del grabador Josep Roca y del llustrador Josep Pascó

Roca fue el responsable del monograma de Miralles $(\mathrm{HM})$ y el superlibro con la leyenda LaborVeritas-Charitas. Pero no solo realizaba planchas para las cubiertas de las encuadernaciones, sino que también esculpió más de veinte retratos de personalidades de la época, estampados, que fueron utilizados para la ilustración para la obra de Emilio Castelar titulada La Revolución religiosa (1880-1883) en cuatro volúmenes.

La trayectoria profesional de Josep Roca tuvo diversos reconocimientos en eventos tan importantes como la Exposición de Industrias Artísticas (1892), la Exposición Internacional de Chicago (1893) y la Exposición de Bellas Artes e Industrias Artísticas (1896).

En la Biblioteca disponemos de 28 encuadernaciones atribuidas y firmadas por este grabador. Sus signaturas son: B-1631; C-4853; C-4854; C4855; C-4856; C-4857; C-4858; C-4859; C-4860; C-4861; C-4862; C-6811; C-7194; G-47 1894; G47 1900; G-47 1901; G-47 1903; L-238; LF-7696; LF-7697; LF-7698; LF-7700; LF-7701; LF-7702; LF-7704; LF-7705; LF-7706; LF-7707.
El segundo de los grabadores que indicamos es Paul Souze, sobrino de Auguste Souze, que se hizo cargo del taller de su tío a partir de 1891-92 trabajando como diseñador y grabador de planchas de cobre para dorar y gofrar e impulsor del sistema de fotograbado. En su taller trabajó durante tres años Josep Roca i Alemany, quien posiblemente estuvo activo hasta la segunda década del siglo XX.

En la Biblioteca y en el Fondo Lafuente Ferrari de la Calcografía Nacional encontramos diez encuadernaciones con grabados firmados y atribuidos a este grabador. Sus signaturas son: C-1697; C1698; C-1688; C-6733 "Figura 2"; C-6734; C6957; C-6958; C-6959; C-7218; LF-4825.
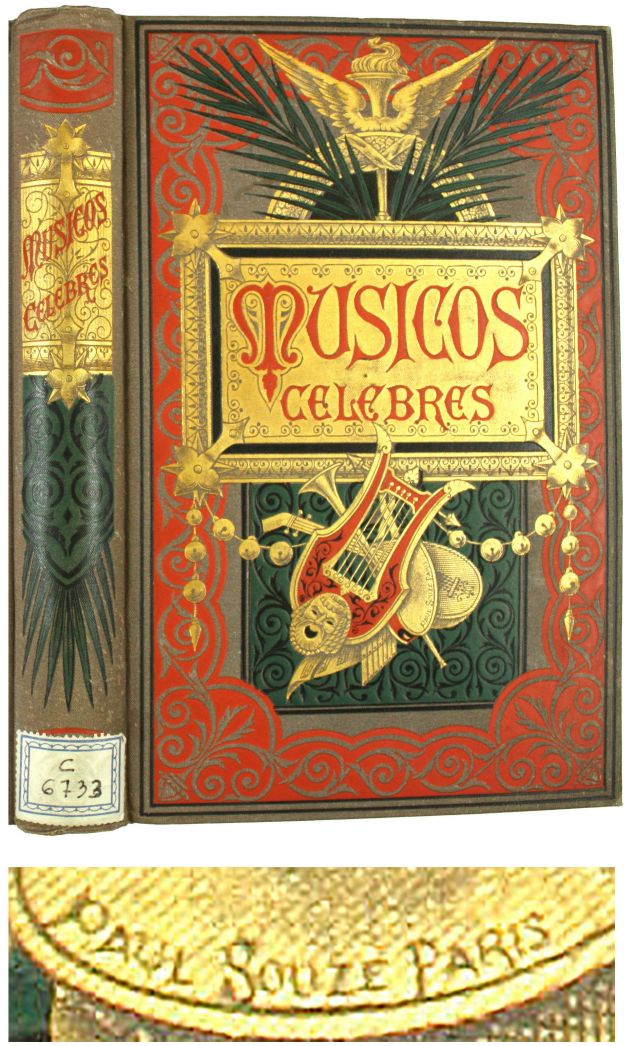

Figura 2. Músicos célebres, 1884 (Sig. C-6733). Firma del grabador Paul Souze

El siguiente de los grabadores que exponemos es Auguste Souze (1829-1900), tío de Paul Souze (1852-1924). Que fue grabador y diseñador francés de planchas para dorar del siglo XIX. Desde 1880, los editores interesados en los avances técnicos venidos de París, enviaban a sus operarios más adiestrados a los talleres de la capital francesa, que tenían a su máximo representante en el grabador Souze, para aprender el nuevo sistema del fotograbado. Solía firmar las planchas de las encuadernaciones industriales en la parte inferior. 
A partir de 1854 comenzó en la empresa Tambon como aprendiz y después como encargado, creando planchas para dorar y gofrar, tanto para encuadernaciones de marroquín como para recubrimientos en papel, además de realizar planchas para tiradas policromadas. La empresa estuvo situada en la calle des Amandiers-Sant-Jacques $n^{\circ} 12$ de París hasta 1855 y en la calle Laplace, $\mathrm{n}^{\circ} 12$ hasta 1867.

Su empresa la inició en 1857; tuvo talleres en Paris en la calle Jean-de-Beauvais hasta 1860 , después en la calle l'École-de-Médecine $n^{\circ} 20$ y por último en la calle de Cherche-Midi $n^{\circ} 79$ hasta 1892 año en que cesa su actividad.
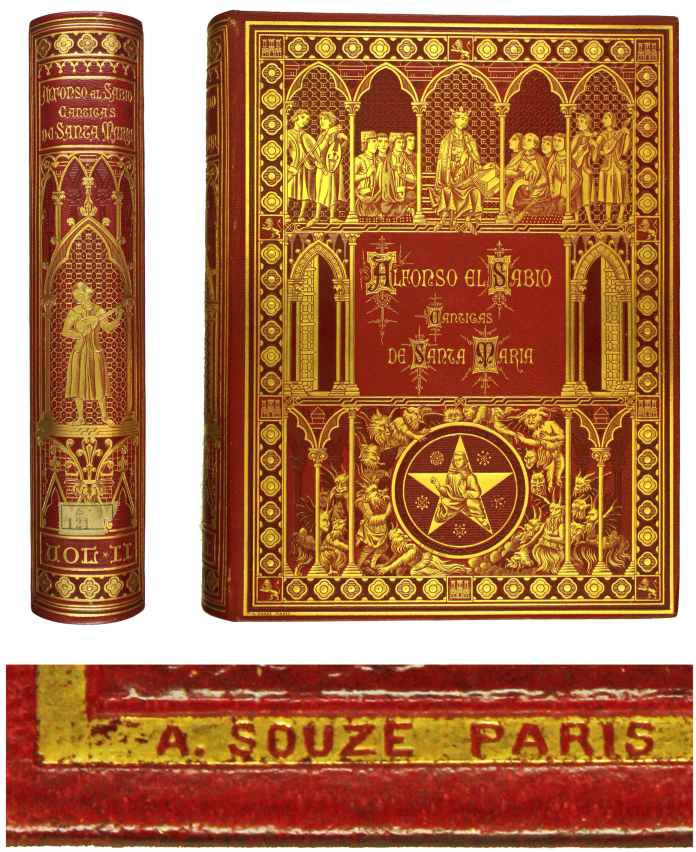

$$
\text { A. MENARD. MADRID - } 1890
$$

Figura 3. Cantigas de Santa María, 1889 (Sig. A-121). Firmas del grabador Auguste Souze y el encuadernador Antonio Menard

En la Biblioteca tenemos tres encuadernaciones con planchas firmadas por este grabador. Sus signaturas son: A-120; A-121 "Figura 3", ambas encuadernadas por Antonio Menard; y C-7185.

El siguiente grabador es Francesc Jorba Curtils (1850-?). Trabajó para las principales editoriales de la época entre ellas Montaner y Simón, Salvat, la Casa Subirana, con los mejores encuadernadores industriales como Eduard Domenech y con los más reconocidos ilustradores del momento como Josép Pascó y Alexandre de Riquer i
Ynglada. Sus firmas pueden aparecer en el interior de la decoración o en las bandas de los encuadramientos exteriores, tanto estampadas en tinta como doradas.
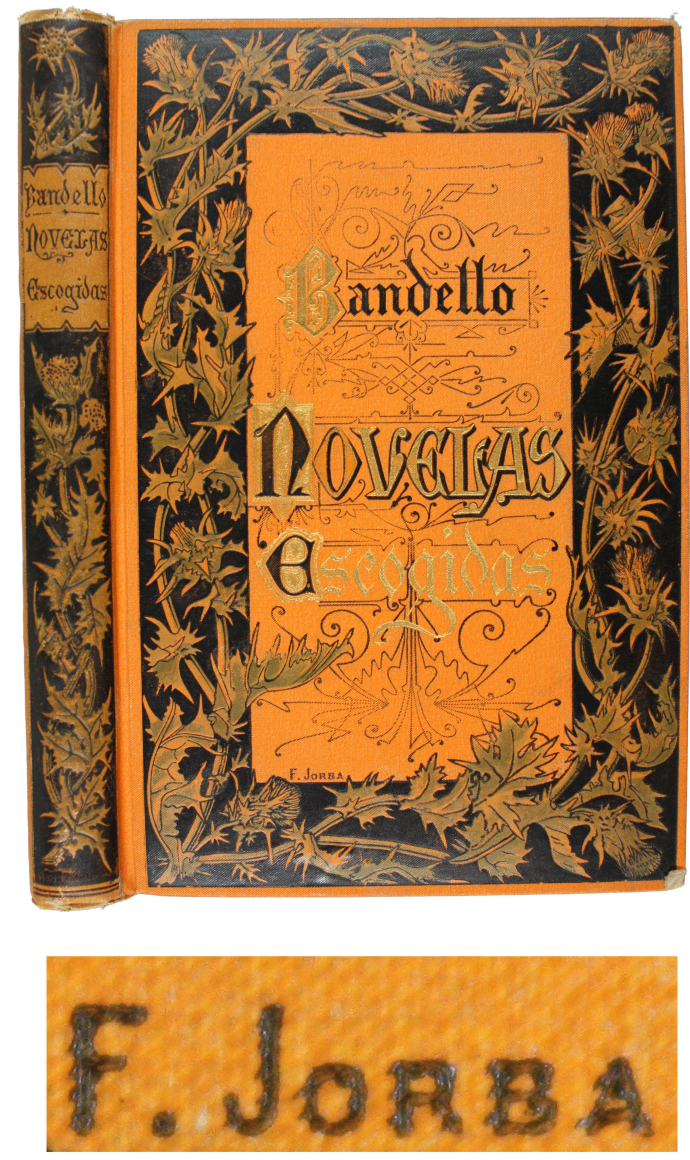

Figura 4. Novelas Escogidas. Biblioteca Arte y Letras, 1884 (Sig. LF-7703). Firma del grabador Francesc Jorba

El oficio de grabador lo aprendió en el taller de Rosend Gelabert, realizando planchas para las encuadernaciones. Por sus trabajos fue galardonado en varias ocasiones como en la Exposición Universal de Barcelona de 1888, en la de Industrias Artísticas de 1892 y en el Concurso de Artes Decorativas de Terrassa en 1894. Trabajó realizando la mayor parte de las planchas de la $B i-$ blioteca Arte y Letras (1881-1890), una de las colecciones más relevantes de finales del siglo XIX. Las dos encuadernaciones con la firma de este grabador, estampada en negro, pertenecen a esta colección y forman parte del Fondo Lafuente Ferrari del Archivo Calcográfico (sig. LF-7703 "Figura 4"; LF-7710).

El último de los grabadores del que tenemos ejemplos en las encuadernaciones de la Real Academia de Bellas Artes es Robert Harbaus, que también fue diseñador y estampador francés de 
mediados del siglo XIX. Tuvo talleres en la calle d'Assas $n^{\circ} .8$ y 7 entre 1854 y 1864 , también en el barrio de Saint-Germain $n^{\circ}$. 8 y por último, en la calle de Palestro en 1867. Su actividad se desarrolló entre 1841 y 1867 . Su producción se centró en la realización de planchas doradas y gofradas, en diseñar herramientas para la encuadernación, además de grabados y dibujos industriales y de ornamentación. En la Biblioteca de la RABASF encontramos una encuadernación industrial con su firma como grabador (sig. C-9095) "Figura 5".

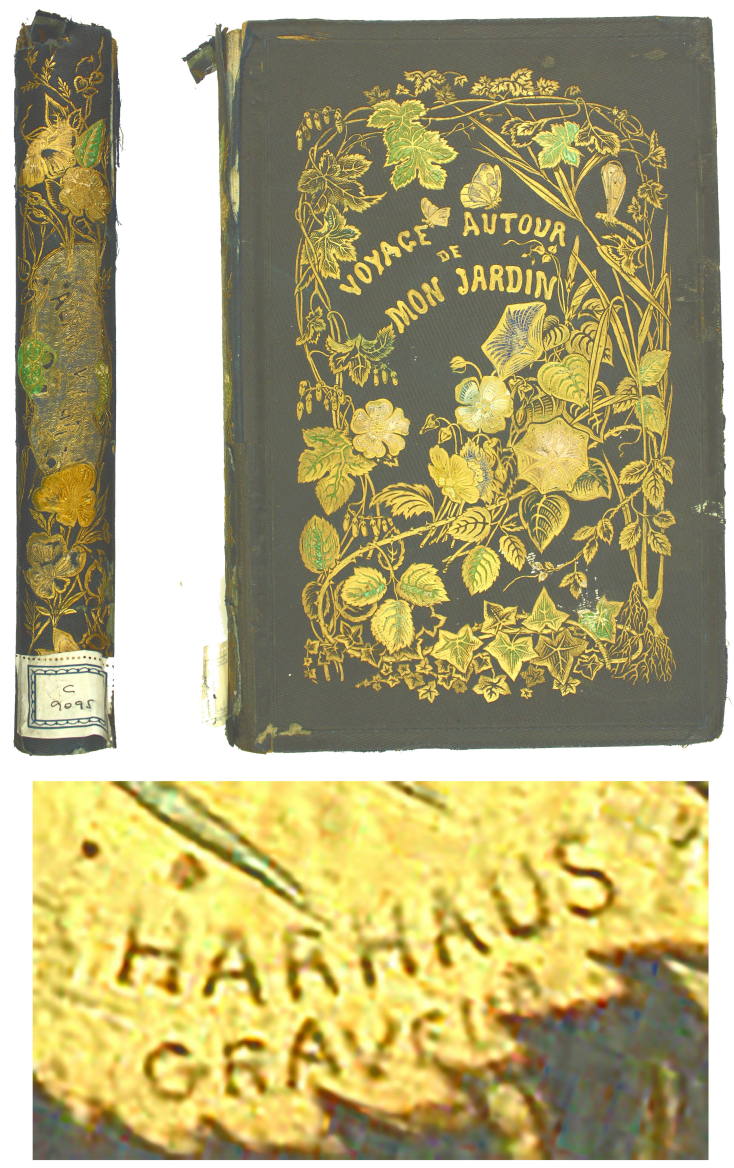

Figura 5. Voyage autor de Mon Jardin, 1851 (Sig. C9095). Firma del grabador Robert Harbaus

\section{Ilustradores}

Podría pensarse que en el ámbito de la encuadernación la figura del ilustrador nace con las encuadernaciones industriales. Sin embargo, antes de que éste fuera considerado, existieron operarios encargados de preparar los diseños que se imprimían, doraban o gofraban en las tapas de las encuadernaciones; sabemos que el mismo Emilio Brugalla diseñaba las decoraciones de sus obras, para después componer los bocetos, marcar y estampar los hierros utilizando varias láminas de pan de oro.
Hemos logrado identificar en 77 encuadernaciones el nombre de ocho ilustradores. En primer lugar tenemos a Henri Marius Michel con 49 diseños, con menor presencia se halló la firma de Josep Vilaseca y Casanovas (once ejemplares con sus diseños), así mismo Josep Pascó y Eulogio Varela con ocho y cinco respectivamente y con tan solo un ejemplar encontramos las firmas en los diseños de Primitivo Carcedo, Tomás Sala, A. Gir y Charles Yriarte.

El primero de los ilustradores que indicamos es Henri Marius-Michel (1846-1925), maestro encuadernador y diseñador francés de los más importantes entre 1880 y 1920 . Es, sin duda, junto a Trautz y Lortic, uno de los más grandes encuadernadores la segunda mitad del siglo XIX y principios del XX.
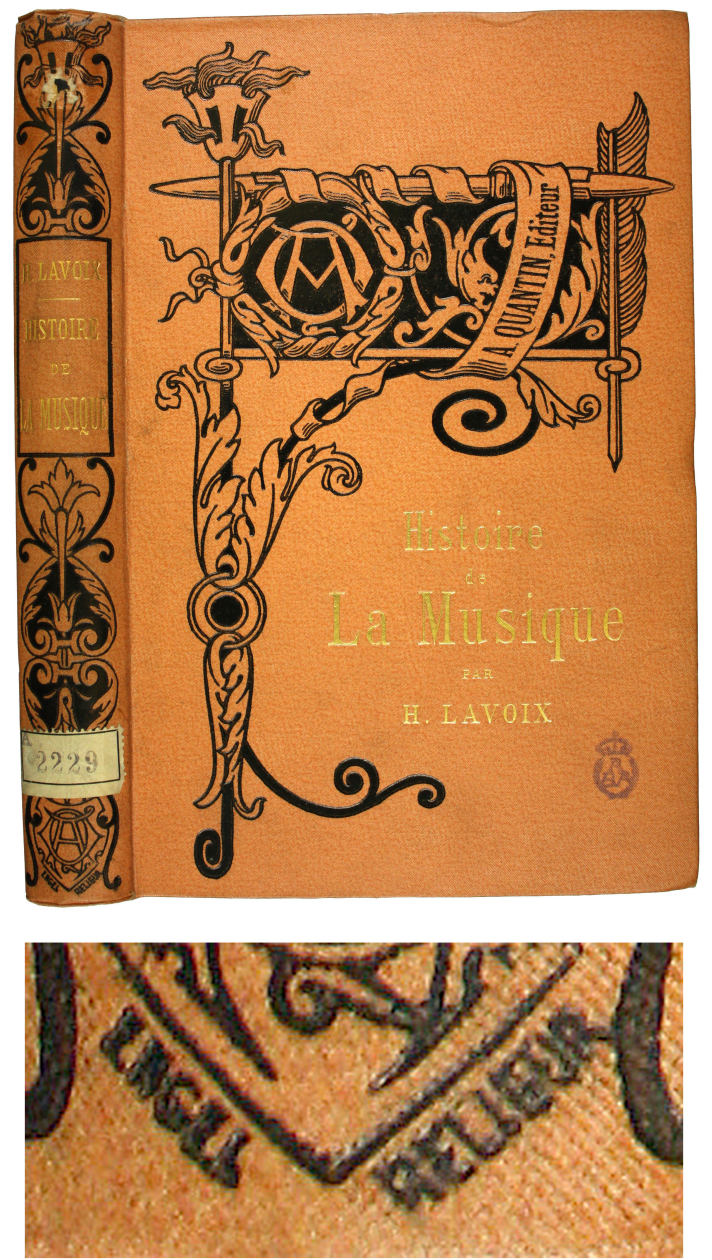

Figura 6. Histoire de la musique, [ca. 1910] (Sig. A2229). Firma del encuadernador Michael Engel

Crea su taller junto a su padre, Jean Michel Marius Michel (1821-1890), en 1876. Diseña un nuevo estilo decorativo basado en plantas ornamentales. Marius-Michel difundió sus ideas en 
varios libros y fue también profesor en la École Estiènne donde enseñó a toda una generación de jóvenes encuadernadores. Su padre trabajó como dorador en el taller de Paul Gruel y colaboró con Ostermann, Duru o Capé.

En la Biblioteca disponemos de 49 encuadernaciones, realizadas por el encuadernador francés Michel Engel (m. 1916), donde muy posiblemente el diseño de las tapas pertenezca a Henri MariusMichel puesto que los frontispicios vienen firmados por este artista. Sus signaturas son: A-633; A-2229 "Figura 6"; A-2230; A-2231; A-2232; L50; L-51; L-53; L-78; L-81; L-82; L-83; L-173; L265; L-266; C-1839; C-3333; C-9104; C-9105; C9106; C-9107; C-9108; C-9110; C-9111; C-9112; C-9113; C-9114; C-9115; C-9116; C-9117; C9118; C-9119; C-9432; C-9731; C-9732; C-9733; C-9734; C-9735; C-9736; C-9737; LF-1267; LF1268; LF-1269; LF-1270; LF-1271; LF-1272; LF1273; LF-1274; LF-1275.

El segundo de los ilustradores en número de ejemplares en la RABASF es el arquitecto, dibujante y acuarelista catalán Josep Vilaseca y Casanovas (1848-1910), el más puro representante del pre-modernismo catalán.

Estudió arquitectura en Madrid y se tituló en 1873. En 1874 ya era profesor de la Escuela de Arquitectura de Barcelona, de la que fue catedrático hasta 1910 año de su muerte. Entre sus alumnos más destacados cabe señalar a los grandes arquitectos del modernismo como son Luís Domènech i Montaner, Antoni Gaudí i Cornet y Josep Puig i Cadafalch.

Vilaseca fue un arquitecto culto y elegante que a través de sus dibujos plenamente detallados producía un corpus inteligente. Viajó con Lluís Domènech i Montaner por Alemania. Después de colaborar con Domènech durante los años 1870, diseñó la fábrica taller para Francisco Vidal y Jevellí (1879-1884), llena de detalles locales dentro de sus referencias clásicas, y el estudio-templo para los hermanos Masriera (1882), aunque profundamente imbuido de la recuperación histórica de la Renaixença. Sus detalles eran refinados, con toda la definición de sus dibujos.

En el Fondo Lafuente Ferrari de la Calcografía Nacional encontramos once encuadernaciones con la firma de este artista (Sig. LF-7696; LF7697; LF-7698; LF-7699; LF-7700 "Figura 7"; LF7701; LF-7702; LF-7704; LF-7705; LF-7706; LF7707).

Con ocho ejemplares firmados encontramos a Josep Pascó Mensa (1855-1910), ilustrador, decorador, dibujante, escenógrafo y coleccionista. Nace en Sant Feliu de Llobregat y muere en Barcelona de un ataque de apoplejía.
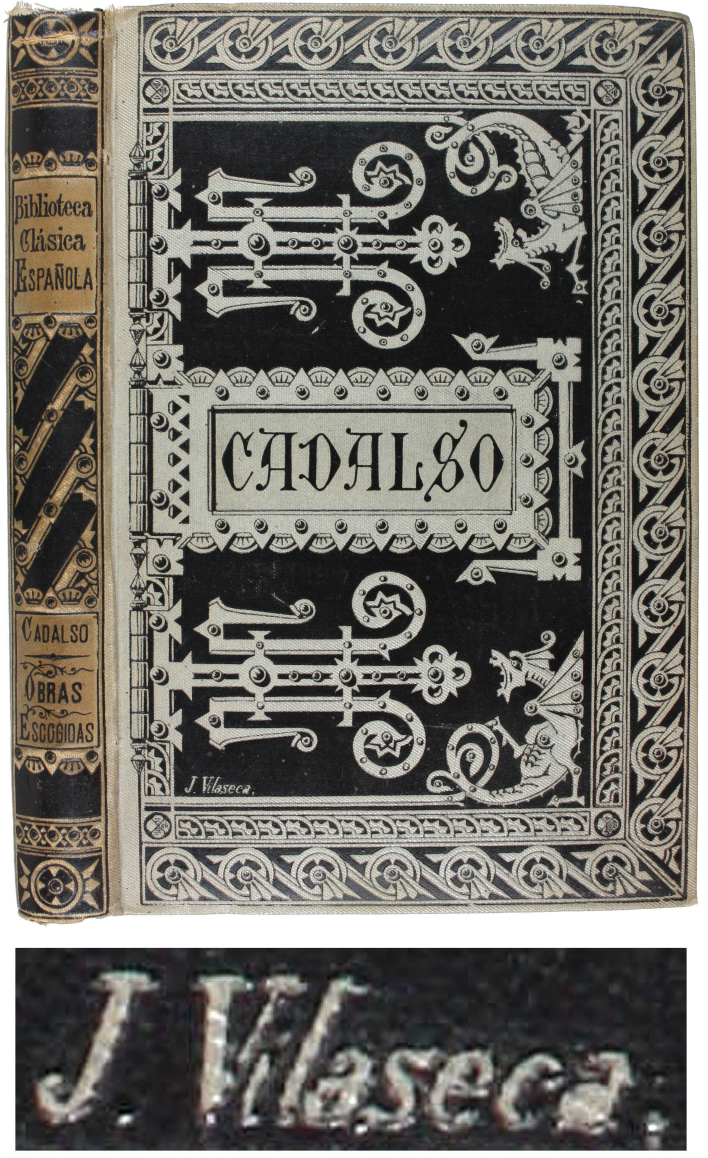

Figura 7. Obras escogidas de D. José Cadalso con una advertencia preliminar, 1885 (Sig. LF-7700).

Firma del ilustrador Josep Vilaseca

Comenzó en el mundo artístico, a la edad de quince años, a través de las escenografías que realizaba para las representaciones teatrales de aficionados de Sant Feliu de Llobregat. Durante algún tiempo se dedicó a la pintura de paisaje, pero por sus excelentes condiciones como decorador decidió dedicarse por entero a la ilustración de libros y la decoración. En 1887 se traslada a Madrid, entrando a trabajar en el taller de escenografía del Teatro Real, decorando también el Teatro Príncipe Alfonso. Al poco tiempo fue contratado para dirigir los talleres del Teatro Nacional de México, donde estuvo algo más de un año, con el cargo de pintor escenógrafo, pintando, entre otras obras, las decoraciones para la ópera Carmen, cuyos bocetos presentó en la III Exposición de Bellas Artes e Industrias Artísticas de Barcelona del año 1896. Regresó a Barcelona donde tuvo una intensa actividad hasta su muerte.

Como ilustrador trabajó para las editoriales más importantes de la época, diseñando cubiertas de libros donde predominaban los colores y composiciones recargadas. Destacan las que hizo para la colección Biblioteca Arte y Letras, las cubiertas 
para la colección Biblioteca Universal (iniciada en 1887), de la Editorial Montaner y Simón, Panorama Nacional editado por Miralles, y las que realizó para las ediciones monumentales y de lujo de esta misma casa, y una muy destacada, la que hizo para el Catálogo de 1900, de la empresa de pavimentos hidráulicos Escofet y Compañía. También trabajó en la ilustración de revistas, como fue el caso de llustración Catalana, donde firmaba bajo el seudónimo de Brisa y dirigió la parte artística de la revista Hispania (18991902). Todo este trabajo tuvo el reconocimiento con varias condecoraciones por sus ornamentaciones para encuadernaciones industriales como la medalla de $3^{\mathrm{a}}$ Clase en la Exposición Nacional de 1887 , de $2^{\mathrm{a}}$ en las de 1890 y 1892, las medallas de oro en las Exposiciones Universales de Barcelona (1888) y París (1889).
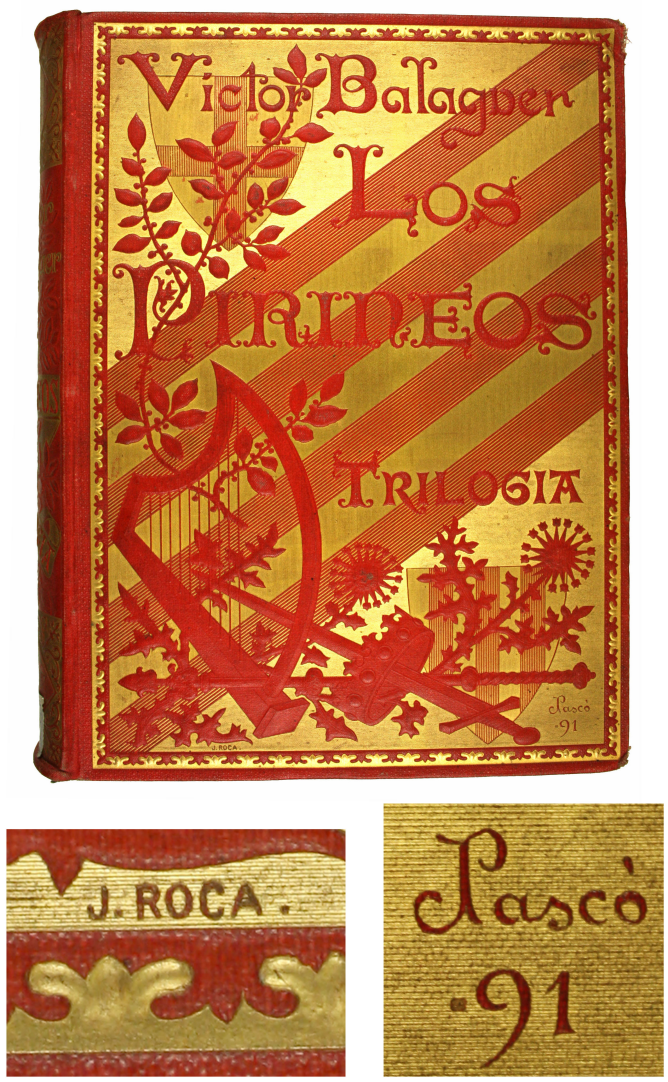

Figura 8. Los Pirineos: trilogía, 1892 (Sig. C-6811). Firma del ilustrador Josep Pascó y del grabador Josep Roca

Dentro de los nuevos avances técnicos en las artes gráficas catalanas, realizó todo tipo de ilustraciones y decoraciones para carteles, como el que hizo para el IV Centenario de Colón (1892). En 1892 fue nombrado profesor de la Escuela Superior de Artes e Industrias de Barcelona, siendo catedrático de Dibujo Decorativo, y encargado de la clase de Composición Decorativa, en la sección de Pintura.

En la Biblioteca encontramos ocho encuadernaciones con la firma de este ilustrador. Tenía como costumbre firmar añadiendo el año de la realización de esa ilustración. Las signaturas de los ejemplares son: C-6811 "Figura 8" donde aparece firmando junto al ilustrados Josep Roca; C8635; C-8636; C-7194; G-47 1894; G-47 1900; G-47 1901; G-47 1903.

El siguiente de los ilustradores es Eulogio Varela Sartorio (1868-1955) importante artista que trabajó como diseñador, ilustrador, pintor y decorador. Impulsó las principales corrientes estéticas europeas a comienzos del siglo XX. Fue uno de los ilustradores que más tiempo estuvo trabajando en Prensa Española, primero en Blanco y Negro y, después, en $A B C$, concretamente, desde 1898 hasta que estalló la Guerra Civil, en 1936, realizando durante ese periodo unos 1.400 trabajos. El primer dibujo que publicó en Blanco y Negro fue El criado del centurión.

Estuvo muy unido a artistas como Picasso, Juan Gris y Emilio Sala, del que fue su maestro. Al primero lo conoció en 1901, cuando el pintor funda en Madrid la revista Arte Joven; con Juan Gris coincidió en Blanco y Negro en 1906.

Nace en el Puerto de Santa María, Cádiz, pero desde muy joven se traslada con su familia a Valladolid y años después a Madrid, donde se matriculó en la Escuela de Bellas Artes de San Fernando e ingresó en el taller de Alejandro Ferrant. En 1897 participó en el famoso concurso para la elección del cartel de Anís el Mono, quedando en tercer lugar. En 1901 decoró, con Emilio Sala, el telón del Teatro Español por encargo de la actriz María Guerrero. Además de Blanco y Negro y $A B C$, colaboró con varias revistas como La llustración Española y Americana, Madrid Cómico, Helios, entre otras.

En 1908 logra la primera medalla en la Exposición Nacional de Bellas Artes. Junto a su producción artística, desarrolló una intensa labor teórica y pedagógica. Fue profesor en la Escuela de Artes y Oficios de Madrid y autor de dos publicaciones de referencia internacional: Temas de composición decorativa y La letra y su teoría constructiva. En 1934 se retiró a su casa de Cercedilla donde murió en 1955.

En la Biblioteca encontramos cinco encuadernaciones con la firma de este artista (sig. REV-833 1900; REV-833 1901; REV-833 1902 "Figura 9"; REV-833 1903; REV-833 1904). 

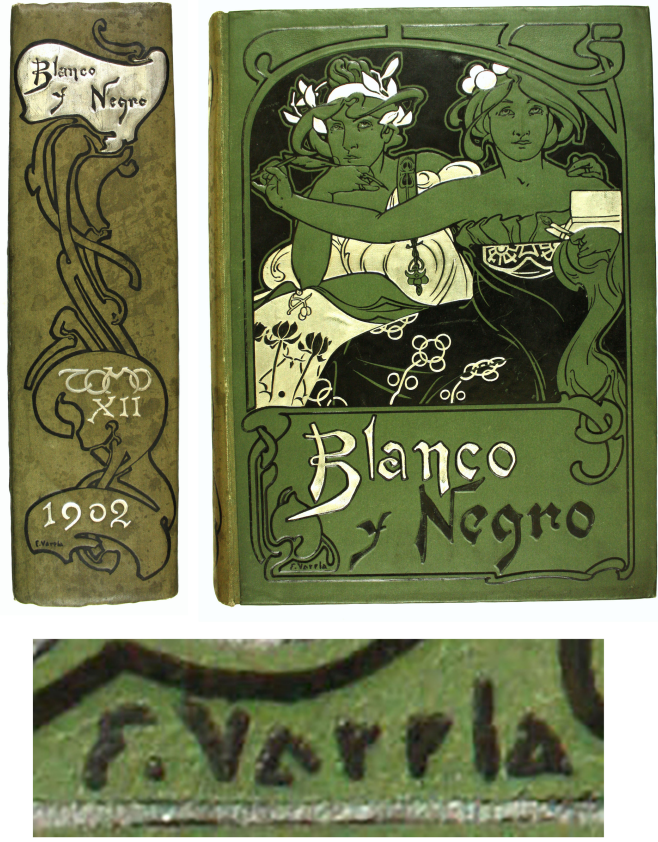

Figura 9. Blanco y Negro: Revista ilustrada, 1902 (Sig. REV-833 1902). Firma del ilustrador Eulogio Varela
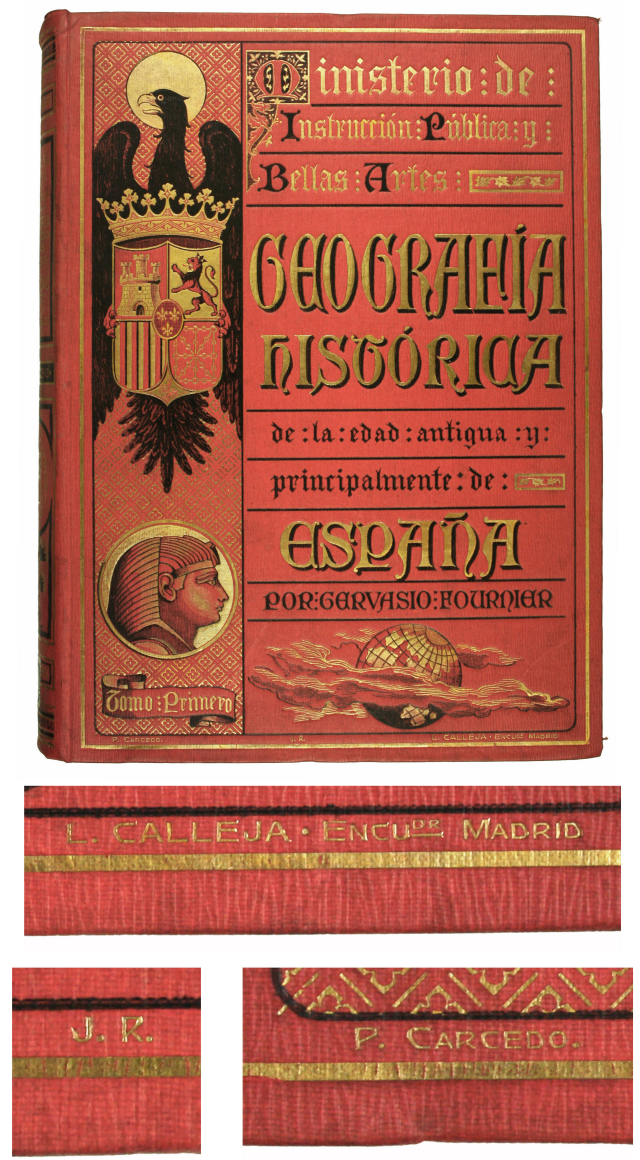

Figura 10. Geografía crítica..., 1910 (Sig. B-1631). Firma del encuadernador Luis Calleja, del grabador Josep Roca y del ilustrador Primitivo Carcedo
De los siguientes cuatro ilustradores solo tenemos un ejemplar de sus diseños. El primero de ellos es el burgalés Primitivo Carcedo Martín ( $n$. 1856). Fue litógrafo y dibujante y uno de los ilustradores de la revista Blanco y Negro que se publicaba todos los domingos en Madrid. También participó en algunas obras como la de Andrés Miralles titulada De mi cosecha, publicada en 1891, con 116 dibujos realizados por él. En el año 1895 participa también con las ilustraciones en la obra de Luis de Ansorena titulada María-Cruz. La Biblioteca Nacional de España tiene una estampa de Primitivo Carcedo con el retrato de Carlos María Francisco de Asís Borbón-Dos Sicilias (sig. BNE IH/1279/3), otra con el retrato de María de las Mercedes de Borbón (Augsburgo) (sig. BNE $\mathrm{IH} / 1249 / 4)$ y la tercera un dibujo con el retrato de Zenón Somodevilla, marqués de la Ensenada (sig. BNE IH/9010/7). En la Biblioteca de la Real Academia de Bellas Artes disponemos de una encuadernación con su firma como ilustrador (sig. B1631) "Figura 10", junto a la de Luis Calleja como encuadernador y Josep Roca como grabador.
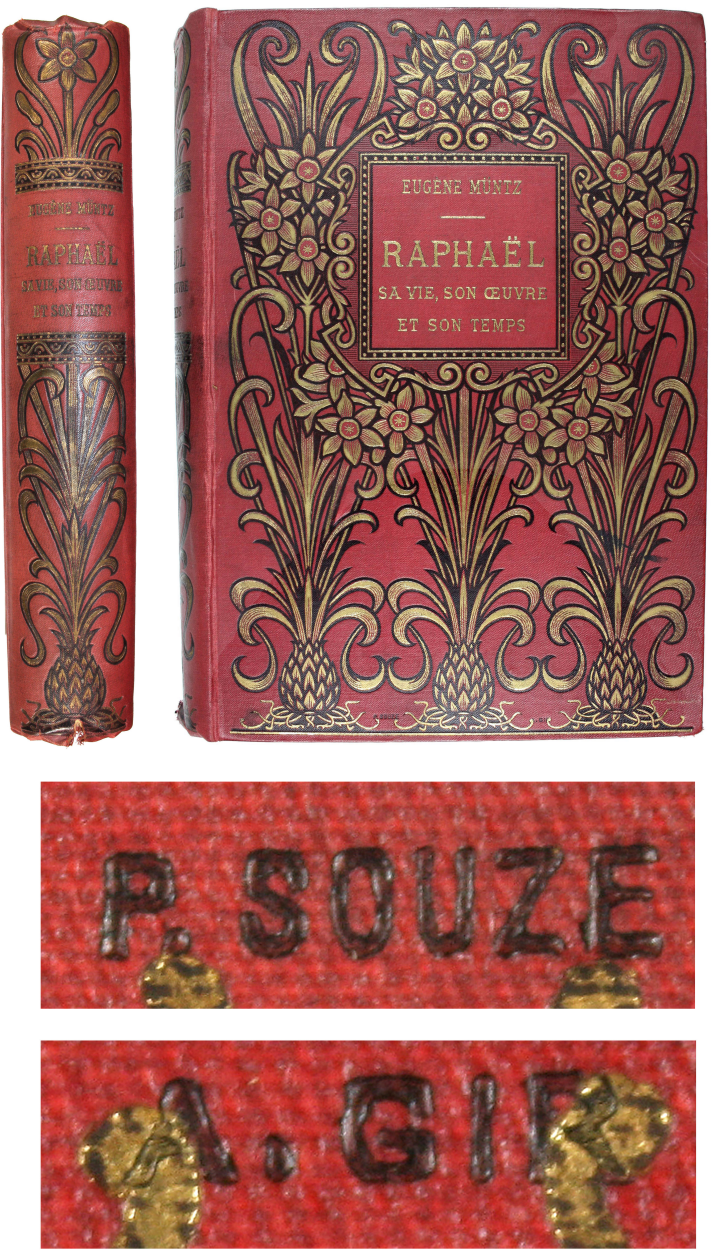

Figura 11. Raphaël, 1923 (Sig. LF-4825). Firma del grabador Paul Souze y del ilustrador A. Gir 
El siguiente ilustrador con un solo ejemplar localizado es A. Gir. Este ilustrador, posiblemente de origen francés, trabajó con grabadores tan importantes como Paul Souze. En el Fondo Lafuente Ferrari del Archivo Calcográfico disponemos de una encuadernación con la firma de este ilustrador (sig. LF-4825) "Figura 11".

El tercero de este grupo de ilustradores es Tomás Sala Gabriel (1857-1952), que trabajó para las ediciones de Salvatella. Como artista y pintor dejó constancia también de su dominio de la acuarela en casi otra decena de portadas, ocupándose especialmente de las relacionadas con la escritora Emilia Pardo Bazán. De este ilustrador encontramos en el Fondo Lafuente Ferrari una encuadernación con su firma (sig. LF-7709) "Figura 12".
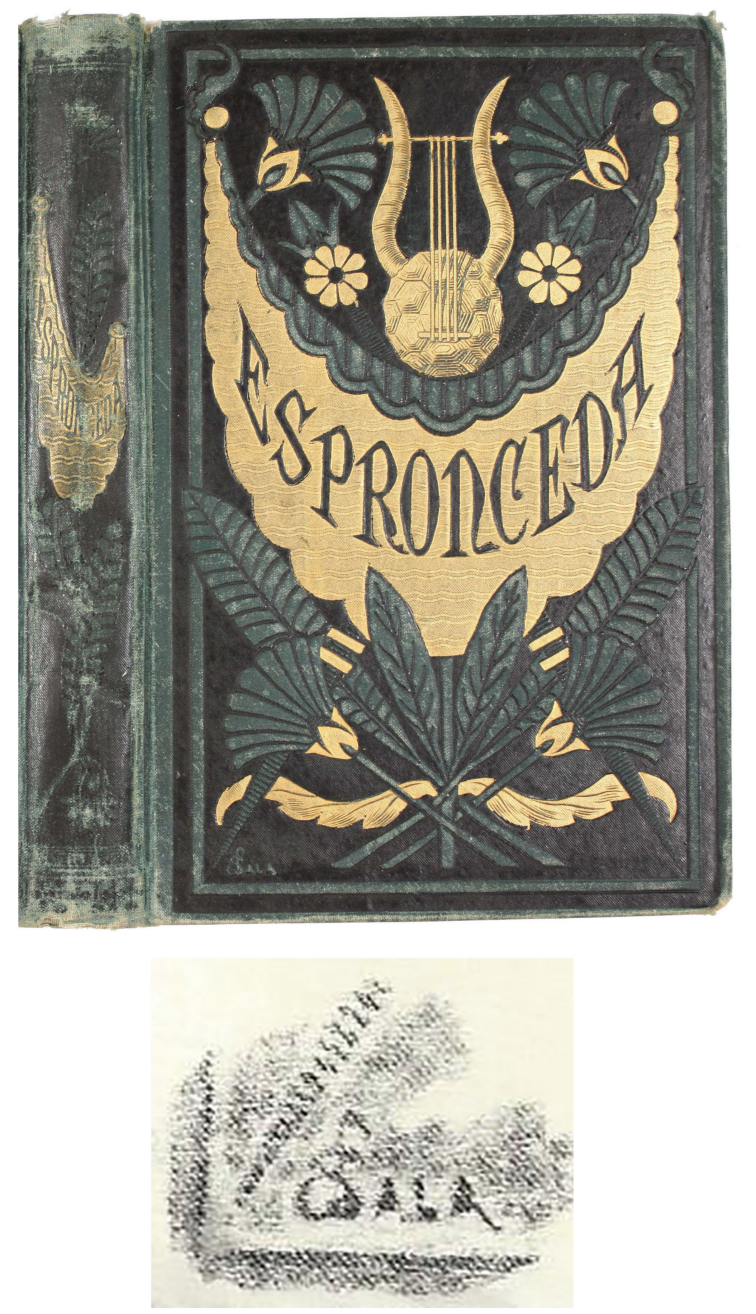

Figura 12. Obras poéticas de Espronceda..., 1883

(Sig. LF-7709). Firma del ilustrador Tomás Sala

El último de los ilustradores del que tenemos ejemplares es el escritor francés de origen español Charles Yriarte (1832-1898). Estudió arqui- tectura en la École des Beaux-Arts y en 1856 llegó a ser inspector de edificios gubernamentales. Más tarde, se enroló en el ejército español como reportero para el periódico Monde illustre y estuvo presente en la campaña de Marruecos. Para esta misma publicación, viajó por España e Italia y llegó a ser redactor tras su vuelta en 1862. En 1871 abandonó su puesto para dedicar su tiempo a viajar y a recoger impresiones de sus viajes en sus trabajos. En el ejemplar que tenemos en la Biblioteca, él es el autor de la obra y también participa en el diseño de las tapas siendo el encuadernador Antoine Lenègre (sig. A-106) "Figura 13".
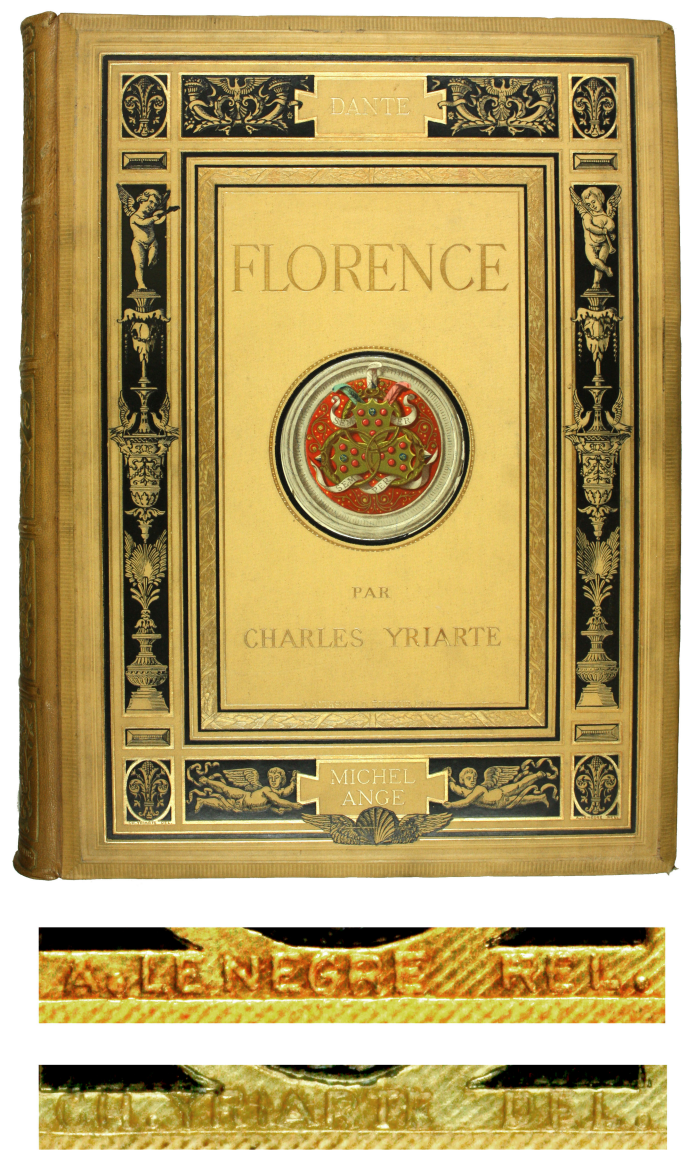

Figura 13. Florence, 1881 (Sig. A-106). Firma del encuadernador Antoine Lenègre y del ilustrador Charles Yriarte

\section{Resultados y conclusiones}

Finalmente hemos identificado además del encuadernador, a ocho ilustradores y cinco grabadores en 121 encuadernaciones, en las que en algunas de ellas aparecía la firma del ilustrador, del grabador además de la del encuadernador.

Como conclusiones podemos apreciar la importancia, en las encuadernaciones industriales o de 
editor, de los ilustradores/diseñadores y de los grabadores, sin los cuales las ornamentaciones de estas tapas no serían igual. Son una tipología de encuadernaciones no muy estudiada pero muy relevante ya que se introdujeron materiales, técnicas constructivas y técnicas decorativas no utilizadas hasta la fecha.

Observamos el trabajo en equipo de los ilustradores, grabadores y encuadernadores, todos ellos de gran renombre y muy cotizados en su época. Las firmas de los artífices favorecen que se puedan conocer los trabajos que realizaron, incluso las fechas de los grabados, además de valorar más estas encuadernaciones, en muchos casos olvidadas, y que nos ayudan a conocer mejor como fueron las encuadernaciones a finales del siglo XIX y primeras décadas del XX, y sus principales artistas.

\section{Referencias}

Bellver Poissenot, Laura (2016). La editorial Montaner y Simón (1868-1981): el esplendor del libro industrial ilustrado (1868-1922). Tesis Doctoral en la Universitat de Barcelona.

Carpallo Bautista, Antonio [et al.] (2015). Encuadernaciones de las Guías de Forasteros de la Real Academia de la Historia. Madrid: Ollero y Ramos, 2015.

Casado Cimiano, Pedro (2006) Diccionario biográfico de ilustradores españoles del siglo XIX. Madrid: Ollero y Ramos, 2006.

Castañeda y Alcover, Vicente (1958). Ensayo de un diccionario biográfico de encuadernadores españoles. Madrid: Maestre, 1958.

Carrión Gútiez, Manuel (1996). La encuadernación española en los siglos XIX y XX. // Historia ilustrada del libro español: la edición moderna. Siglos XIX y XX. Madrid: Fundación Germán Sánchez Ruipérez; Pirámide, 1996. 491539.
López Serrano, Matilde (1951). El encuadernador catalán del siglo XIX Pedro Doménech. // Revista Bibliográfica y Documental. t. V, 1-4 (1951) 167-178.

López Serrano, Matilde (1972). La encuadernación española: breve historia. Madrid: Asociación Nacional de Bibliotecarios, Archiveros y Arqueólogos, 1972.

Quiney Urbieta, Aitor (2004). Breves notas sobre algunos encuadernadores catalanes (1840-1929). // Encuadernación de Arte. 24 (2004) 19-29.

Quiney Urbieta, Aitor (2006). La encuadernación artística catalana 1844-1929. Trabajo Fin de Máster.

Quiney Urbieta, Aitor (2005). Hermenegildo Miralles, artes gràfiques, enquadernaciò. Exposició a la Biblioteca de Catalunya. Barcelona: Biblioteca de Catalunya, 2006.

Rovira y Adán, Jaime (1901-1902). Don Pedro Doménech y Saló, encuadernador. // Revista Gráfica. (1901-02) 56-60.

Sánchez Vigil, Juan Miguel (2008). Revistas ilustradas en España. Del Romanticismo a la guerra civil. Gijón: Trea, 2008.

Trenc Ballester, Eliseu (2000). Alexandre de Riquer. Barcelona: Lunwerg, 2000.

Trenc Ballester, Eliseu (1977). Les arts gràfiques de l'època modernista a Barcelona. Barcelona: Gremi d'Indústries Gràfiques, 1977.

Vélez Vicente, Pilar (1989). Catàleg del Museu de les Arts GRàfiques. La col.lecció Josep Roca i Alemany. Barcelona. Ajuntament, 1989.

Vélez Vicente, Pilar (1999). La encuadernación industrial del modernismo en Catalunya // Encuadernación de Arte. 13 (1999) 71-74.

Vélez Vicente, Pilar (1996). La ilustración del libro en España en los siglos XIX y XX // Historia ilustrada del libro español: la edición moderna. Siglos XIX y XX. Madrid: Fundación Germán Sánchez Ruipérez; Pirámide, 1996. 195237

Vélez Vicente, Pilar (1988). En pro de les arts industrials: J. Roca i Alemany i el cuir repussat. // D'art. 14 (1988) 8597.

Enviado: 2019-02-28. Segunda versión: 2019-06-04 Aceptado: 2019-06-04. 